\title{
Radiographic illusion of cardiomegaly resulting from a pulmonary blastoma in a patient imaged for evaluation of chronic bronchitis
}

\author{
Swaroop Revannasiddaiah, ${ }^{1}$ Bhaskar Bhardwaj, ${ }^{2}$ Sridhar Papaiah Susheela, ${ }^{3}$ \\ Shivaprakash Basavanthaiah Hiremath ${ }^{4}$
}

${ }^{1}$ Department of Radiotherapy \& Clinical Oncology, Swami Rama Cancer Hospital \& Research, Institute, Haldwani, Uttarakhand, India ${ }^{2}$ Department of Cardiology, Indira Gandhi Medical College, Shimla, Himachal Pradesh, India

${ }^{3}$ Department of Radiation Oncology, HealthCare GlobalBangalore Institute of Oncology, Bengaluru, Karnataka, India ${ }^{4}$ Department of Radiology, Pushpagiri Institute of Medical Sciences and Research, Tiruvalla, Kerala, India

\section{Correspondence to} Dr Swaroop Revannasiddaiah; swarooptheone@gmail.com

\begin{tabular}{l} 
To cite: Revannasiddaiah S, \\
Bhardwaj B, Susheela SP, \\
et al. BMJ Case Rep \\
Published online: [please \\
include Day Month Year] \\
doi:10.1136/bcr-2013- \\
010179 \\
\hline
\end{tabular}

\section{DESCRIPTION}

Cardiomegaly is conveniently defined by a simple and time-tested method, using a posteroanterior chest radiograph obtained in mid-inspiration, as a 'cardiothoracic ratio greater than 0.5 '. The cardiothoracic ratio is in turn calculated by measuring the distance from the midline to the most lateral aspect of the left and right cardiac silhouette borders, and dividing the sum by the maximum horizontal measurement of the thorax, from the left to right pleural surface at the level of the diaphragmatic apices. ${ }^{1}$

The accompanying images belong to a man who presented with symptoms of dyspnoea, cough and thoracic pain. The patient had earlier been diagnosed to be suffering from chronic bronchitis. On the assumption of an acute exacerbation of chronic bronchitis, a chest radiograph (figure 1) was obtained as part of the initial evaluation. Surprisingly, the radiograph seemed to depict an enlarged cardiac silhouette, which by appearance happened to fulfil the Danzer criteria for assigning a radiological diagnosis of 'cardiomegaly'.

However, further evaluation with sectional imaging (figure 2) demonstrated the cause behind the illusion of 'cardiomegaly' to be a solid mass lesion located posterolateral to the heart. Biopsy revealed the histopathology to be consistent with a

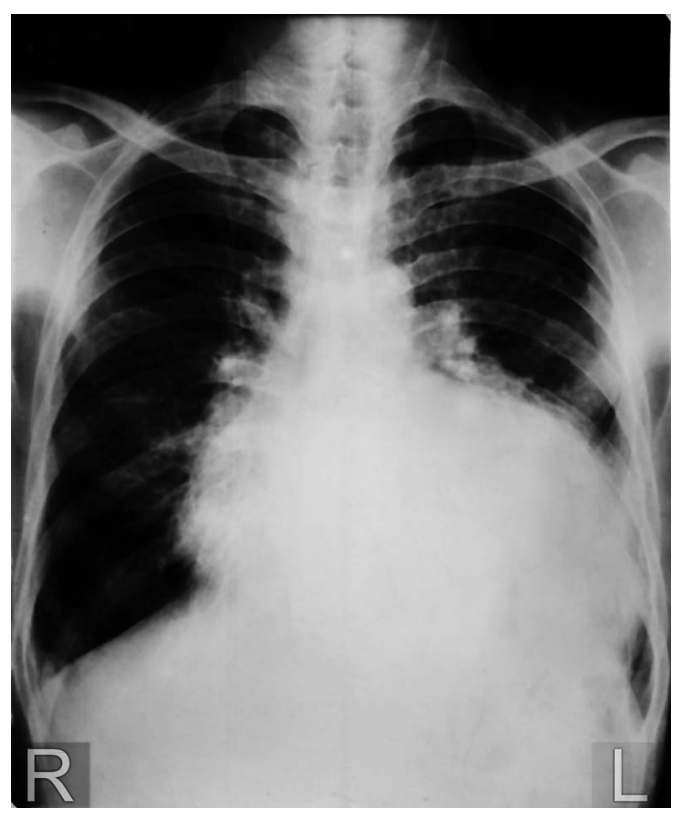

Figure 1 Posteroanterior chest radiograph demonstrating the appearance of an enlarged cardiac silhouette.

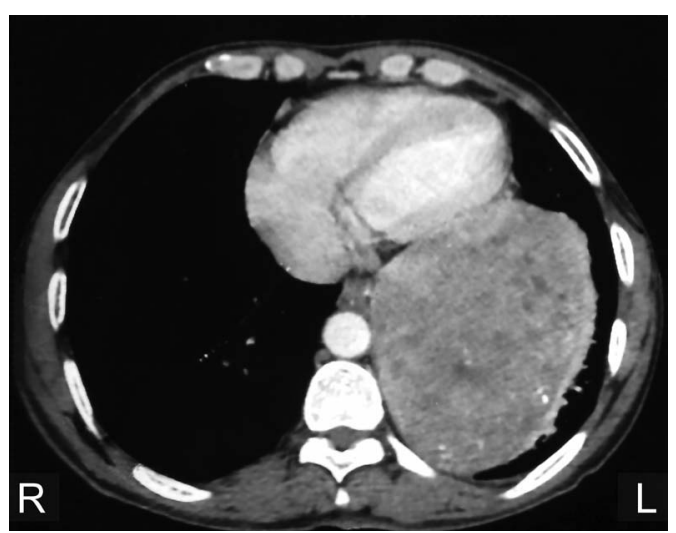

Figure 2 Visualisation on an axial CT slice of the solid mass lesion situated posterior and lateral to the heart.

biphasic-pulmonary blastoma, which are called so since they demonstrate the presence of both epithelial and mesenchymal components. Positive staining was noted for pan-cytokeratin, desmin, vimentin and epithelial membrane antigen. Subsequent to surgical resection, further treatment was with adjuvant chemotherapy based on dacarbazine and doxorubicin. At a follow-up of 2 years, the patient remains free of disease.

\section{Learning points}

- The cardiothoracic ratio (on a posteroanterior view thoracic radiograph obtained in inspiration) is calculated by measuring the distance from the midline to the most lateral aspect of the left and right cardiac silhouette borders (left apical and right atrial silhouettes), and dividing the sum by the maximum horizontal measurement of the thorax, from the left to right pleural surface at the level of the diaphragmatic apices. In rare situations, a mass lesion situated posterior/adjacent to the heart may be a differential diagnosis to (pseudo)cardiomegaly as visualised on a chest radiograph.

- Pulmonary blastomas are rare tumours (accounting for $0.25-0.5 \%$ of all adult lung malignancies) and the sparse evidence available from case reports and series points towards initial surgical resection with adjuvant chemotherapy based on doxorubicin and dacarbazine as being the mainstay of optimal treatment. $^{23}$ 
Contributors SR initiated the article and provided the images. BB and SBH wrote the manuscript. HB performed the literature search. SPS finalised the article.

Competing interests None.

Patient consent Obtained.

Provenance and peer review Not commissioned; externally peer reviewed.

\section{REFERENCES}

1 Danzer CS. The cardiothoracic ratio. Am J Med Sci 1919;157:513-21.

2 Koss MN, Hochholzer L, O'Leary T. Pulmonary blastomas. Cancer 1991;67: 2368-81.

3 Van Loo S, Boeykens E, Stappaerts I, et al. Classic biphasic pulmonary blastoma: a case report and review of the literature. Lung Cancer 2011;73:127-32.

Copyright 2013 BMJ Publishing Group. All rights reserved. For permission to reuse any of this content visit http://group.bmj.com/group/rights-licensing/permissions.

BMJ Case Report Fellows may re-use this article for personal use and teaching without any further permission.

Become a Fellow of BMJ Case Reports today and you can:

- Submit as many cases as you like

- Enjoy fast sympathetic peer review and rapid publication of accepted articles

- Access all the published articles

- Re-use any of the published material for personal use and teaching without further permission

For information on Institutional Fellowships contact consortiasales@bmjgroup.com

Visit casereports.bmj.com for more articles like this and to become a Fellow 